\title{
Karyotype and male meiosis in Spartocera batatas and meiotic behaviour of multiple sex chromosomes in Coreidae (Heteroptera)
}

\author{
María José FRANCO ${ }^{1}$, María José BRESSA ${ }^{1,2}$ and Alba Graciela PAPESCHI ${ }^{1,2 *}$ \\ ${ }^{1}$ Laboratorio de Citogenética y Evolución, Departamento de Ecología, Genética y Evolución, Facultad de Ciencias Exactas y \\ Naturales, Universidad de Buenos Aires, Buenos Aires, Argentina; e-mail: alpape@ege.fcen.uba.ar \\ ${ }^{2}$ Members of the Carrera del Investigador Científico (CONICET)
}

Keywords. Holokinetic chromosomes, multiple sex chromosomes, C-banding, fluorescent-banding, karyotype evolution, Heteroptera

\begin{abstract}
The Coreidae (Heteroptera) have holokinetic chromosomes and during male meiosis the autosomal bivalents segregate reductionally at anaphase I while the sex chromosomes do so equationally. The modal diploid chromosome number of the family is $2 \mathrm{n}=21$, with a pair of m-chromosomes and an X0/XX sex chromosome system. A $2 \mathrm{n}=24 / 26$ (male/female) and an $\mathrm{X}_{1} \mathrm{X}_{2} 0 / \mathrm{X}_{1} \mathrm{X}_{1} \mathrm{X}_{2} \mathrm{X}_{2}$ sex chromosome system were found in Spartocera batatas (Fabricius). C-banding and fluorescent-banding revealed the presence of AT-rich heterochromatic bands medially located on all the autosomes, and one telomeric band on both the $\mathrm{X}_{1}$ and $\mathrm{X}_{2}$ chromosomes. This banding pattern differed from the telomeric heterochromatin distribution found in most other heteropteran species. The $\mathrm{X}_{1}$ and $\mathrm{X}_{2}$ chromosomes were intimately associated during male meiosis and difficult to recognize as two separate entities. Based on a comparison with the behaviour of sex chromosomes in other coreids and other heteopterans with multiple sex chromosomes it is suggested that the particular behaviour of $\mathrm{X}_{1}$ and $\mathrm{X}_{2}$ chromosomes in coreid species with multiple sex chromosome systems evolved as an alternative mechanism for ensuring the proper segregation of the sex chromosomes during meiosis.
\end{abstract}

\section{INTRODUCTION}

The Coreidae include at least 250 genera and 1800 species, which are distributed worldwide, but are more abundant in the tropics and subtropics. Coreids are all phytophagous; most species feed on the vascular systems of plants and some are of economic importance (Schuh \& Slater, 1995). Spartocera batatas (Fabricius) (subfamily Coreinae, tribe Spartocerini) causes damage to sweet potato Ipomoea batatas (Linnaeus) in Puerto Rico and Jamaica, and is also encountered in Brazil and Argentina (Schaefer \& Panizzi, 2000).

From a cytogenetic point of view, the Coreidae possess holokinetic chromosomes and the males show a prereductional type of meiosis for the autosomes and postreductional for the sex chromosomes. Autosomal bivalents with terminal chiasmata segregate reductionally at anaphase I and divide equationally at anaphase II, while the sex chromosomes divide into chromatids during the first meiotic division and segregate reductionally in the second. The diploid chromosome number of the family ranges from 13 to 28 with the modal number of $2 n$ $=21$, which is present in 47 out of the 106 species cytogenetically analyzed (44.3\%) (Fig. 1) (Ueshima, 1979; Manna et al., 1985; Papeschi \& Bressa, in press). The Coreidae are also characterized by a pair of m-chromosomes, which are found in $80.4 \%$ of the species. This chromosome pair differs in behaviour from the autosomes and sex chromosomes; i.e., the $\mathrm{m}$-chromosomes are achiasmatic, associate in a pseudobivalent at metaphase I and segregate pre-reductionally at anaphase I (Ueshima 1979; Bressa et al., 2001; Cattani et al., 2004; Cattani \& Papeschi, 2004; Bressa et al., 2005). However, one exception to this meiotic behaviour is described in Coreus marginatus Linnaeus by Nokkala (1986) and Suja et al. (2000), who reported that the $\mathrm{m}$-chromosomes were present as a bivalent in some cells. The most common sex chromosome system of the family is $\mathrm{X} 0 / \mathrm{XX}$ (male/female) $(63.3 \%)$ followed by the multiple system $\mathrm{X}_{1} \mathrm{X}_{2} 0 / \mathrm{X}_{1} \mathrm{X}_{1} \mathrm{X}_{2} \mathrm{X}_{2}$ (32.7\%) (Ueshima, 1979; Papeschi et al., 2003, Cattani et al., 2004; Cattani \& Papeschi, 2004; Bressa et al., 2005). Three species of Acanthocephala Laporte are reported as having an XY/XX system (Wilson, 1907, 1909) and a multiple system of $\mathrm{X}_{1} \mathrm{X}_{2} \mathrm{X}_{3} 0$ in males has been ascribed to one population of Coreus marginatus (Xavier, 1945).

Most reports on C-positive heterochromatin distribution in Heteroptera describe the C-bands as terminally located, but in a few species interstitial blocks have been observed (Camacho et al., 1985; Panzera et al., 1995; Grozeva \& Nokkala, 2001; Grozeva et al., 2004; Ituarte \& Papeschi, 2004; Bressa et al., 2005). Heterochromatin characterization has shown that C-bands are generally DAPI bright and CMA dull, and in the few species, in which CMA bright bands were detected they correspond to nucleolus organizing regions (González-García et al., 1996; Papeschi \& Bressa, 2002; Papeschi et al., 2003; Rebagliati et al., 2003; Cattani \& Papeschi, 2004).

A previous report on species belonging to the tribe Spartocerini refer to Spartocera fusca (Thunberg), a species with a diploid number $2 \mathrm{n}=20+2 \mathrm{~m}+\mathrm{X} 0 / \mathrm{XX}$ (male/female) (Cattani \& Papeschi, 2004). In the present

\footnotetext{
* Corresponding author.
} 


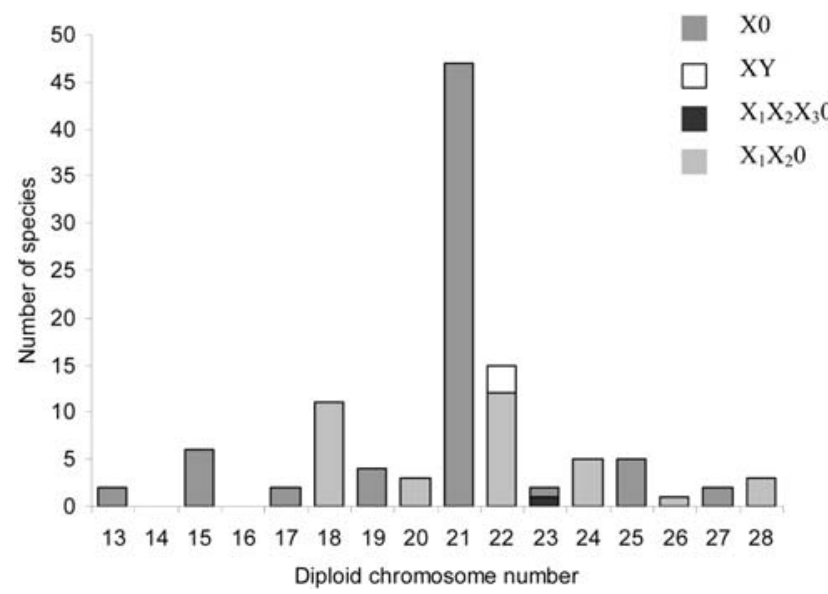

Fig. 1. Diploid chromosome numbers and sex chromosome systems in Coreidae.

work the karyotype and male meiosis of $S$. batatas were analyzed. The results of C-banding and DAPI/CMAbanding are also presented and compared with previous reports on S. fusca; in the light of our results the diploid number of the latter is revised.

\section{MATERIAL AND METHODS}

Twenty six males and five females of Spartocera batatas from Posadas, Misiones Province (Argentina) were analyzed. All specimens were fixed in the field in $3: 1$ absolute ethanol : glacial acetic acid. Male and female gonads were dissected under a binocular stereoscopic microscope, and the testes and ovarioles were kept in $70 \%$ ethanol at $4^{\circ} \mathrm{C}$. Slides were prepared by the squash technique in acetic haematoxylin. Some other slides were prepared in $45 \%$ acetic acid and the cover slip was removed by the dry ice method. C-banding and DAPI/CMAbanding techniques were performed according to previous reports (Papeschi, 1988; Rebagliati et al., 2003).

Three adult females and five adult males of Spartocera fusca from Hughes, Santa Fe Province (Argentina) were analyzed by standard techniques in order to corroborate the male and female diploid number from spermatogonial and oogonial prometaphases, respectively.

\section{RESULTS}

\section{Karyotype and male meiosis in Spartocera batatas}

The chromosome complement of $S$. batatas is $2 \mathrm{n}=$ $24 / 26=20+2 m+X_{1} X_{2} 0 / 20+2 m+X_{1} X_{1} X_{2} X_{2}$ (male/female). Autosomes gradually decrease in size and the m-chromosomes are the smallest of the complement. A subterminal secondary constriction was observed in one of the largest autosomal pairs (Fig. 2a). In spermatogonial (Fig. 2a) and oogonial prometaphases the pair of $\mathrm{m}$-chromosomes were easily recognized, while the $\mathrm{X}$ chromosomes can not be identified, since they are of medium size.

In male meiosis, the $\mathrm{X}_{1}$ and $\mathrm{X}_{2}$ chromosomes were very intimately associated from pre-meiotic interphase until telophase II, making their recognition as two different entities difficult. In a few cells, where they were a little separated, a slight size difference was evident. At pachytene, autosomal bivalents were associated at posi- tively heteropycnotic regions, and the sex chromosomes were at the periphery of the nucleus (Fig. 2b). After diplotene (Fig. 2c) the cell entered a diffuse stage, in which the sex chromosomes remained condensed and the autosomes decondensed completely (Fig. 2d); the $\mathrm{m}$-chromosome pair could not be identified until diakinesis (Fig. 2c-e). Bivalents recondensed during diakinesis and always showed only one chiasma, which was generally medially located (Fig. 2e, f). At this stage the $\mathrm{m}$-chromosomes were separate and negatively heteropycnotic (Fig. 2f); as prophase progressed the m-univalents moved together until they associated non-chiasmatically and formed a pseudo-bivalent (pIIm) (Fig. 2g). In the first meiotic division, the autosomal bivalents were arranged on the metaphase plate in a ring configuration, with the $\mathrm{m}$ pseudo-bivalent located at its center and the $\mathrm{X}_{1}-\mathrm{X}_{2}$ chromosomes lying outside the ring (Fig. $2 \mathrm{~g}$ ). At anaphase I, the autosomes and the $\mathrm{m}$ pair segregated reductionally, but the sex chromosomes divided equationally; all of them migrated synchronously. Second meiotic division followed without interkinesis, and at metaphase II the autosomes and the $\mathrm{m}$ chromosomes were arranged as before, while the sex chromosomes were on an accessory plate (Fig. 2h). At anaphase II-telophase II, the sex chromosomes migrated to one pole and decondensed later than autosomes (Fig. 2i). A single nucleolus was observed associated with one of the largest autosomal bivalents from an early meiotic stage until diakinesis (Fig. $2 \mathrm{c}-\mathrm{f}$ ), and in some cells could still be detected at anaphase I.

\section{Diploid chromosome complement of Spartocera fusca}

In a previous paper on S. fusca Cattani \& Papeschi (2004) report $2 \mathrm{n}=23 / 24$ (male/female) based on an analysis of male meiosis. Furthermore, the " $\mathrm{X}$ chromosome" presented a particular morphology that was interpreted as a secondary constriction. In view of our present results on $S$. batatas, a careful analysis of spermatogonial and oogonial cells was conducted in order to confirm the diploid chromosome number of $S$. fusca. Our present results revealed that the chromosome complement of this species is $2 \mathrm{n}=24 / 26$ (male/female), with a pair of m-chromosomes.

\section{C-banding and fluorescent-banding in $S$. batatas}

All bivalents (excluding the m-chromosome pseudobivalent) had conspicuous interstitially located C-positive bands, and some of them also had small C-positive bands in the telomeric regions (Fig. 3). During pachytene, autosomal bivalents associated via their C-positive heterochromatin and from two to four C-positive chromocentres were observed (Fig. 3b, c). At diakinesis, C-bands were detected flanking the chiasmata (Fig. 3d-i). Each sex chromosome had only one C-positive band on its telomeric region.

DAPI/CMA-staining revealed that the C-positive heterochromatin of all the chromosomes is DAPI bright/CMA dull (Fig. 4). The only exception was the $\mathrm{m}$-chromosome pair, which was $\mathrm{C}$-negative and DAPIdull. 

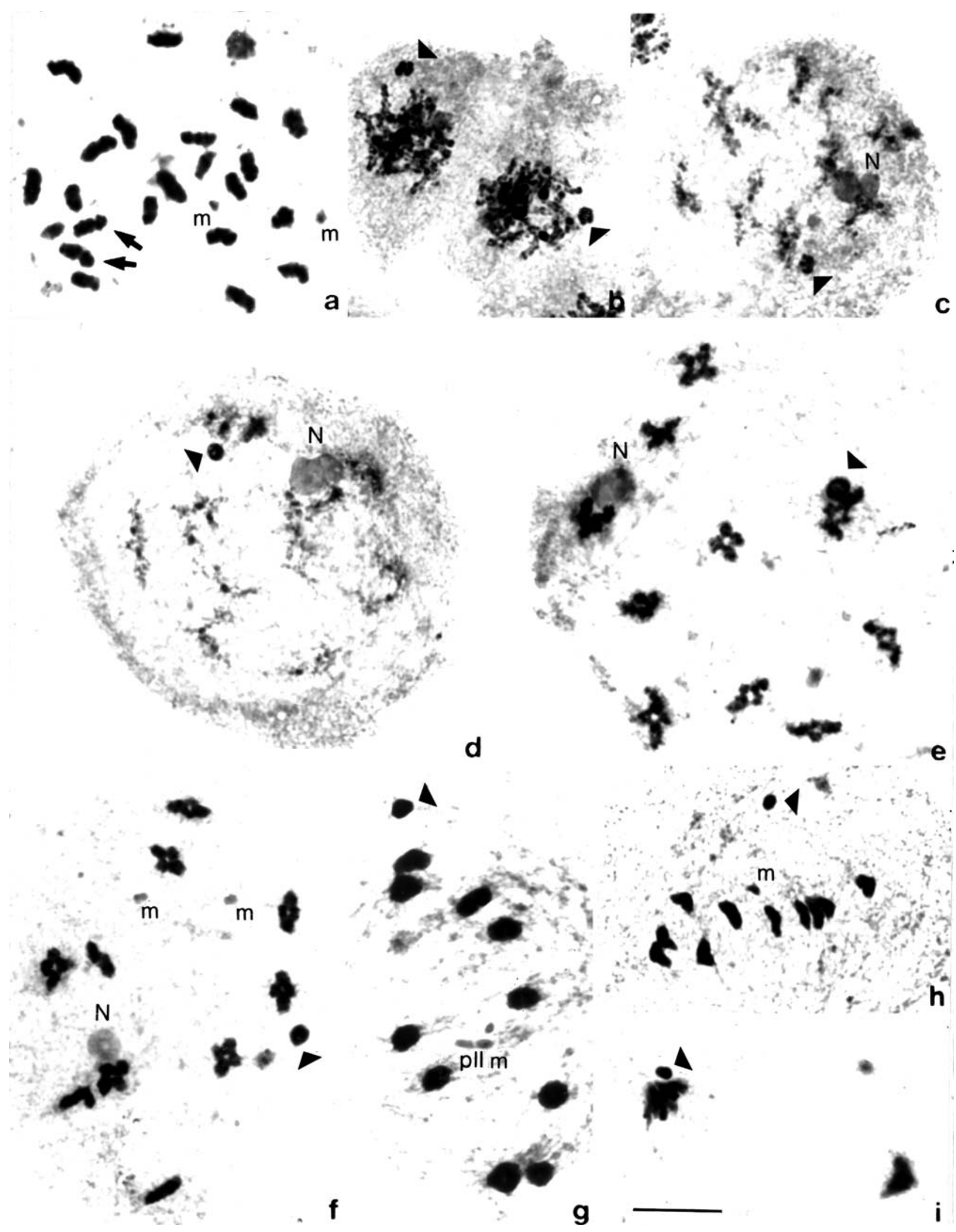

Fig. 2. Spermatogenesis of Spartocera batatas. $2 n=24=20+2 m+X_{1} X_{2} 0$. a) Spermatogonial prometaphase; arrows indicate one of the largest autosomal pairs with a secondary constriction. $\mathrm{b}$ - pachytene; $\mathrm{c}$ - diplotene; in (b) and (c) the sex chromosomes are closely associated side by side. $\mathrm{d}$ - diffuse stage; the $\mathrm{X}_{1}$ and $\mathrm{X}_{2}$ sex chromosomes are no longer distinct but form a single body; $\mathrm{e}-$ early diakinesis; $\mathrm{f}$ - late diakinesis; $\mathrm{g}$ - metaphase I; $\mathrm{h}$ - metaphase II; $\mathrm{i}$ - telophase II. Arrowheads indicate the sex chromosomes. $\mathrm{N}=$ nucleolus. $\mathrm{m}=\mathrm{m}$-chromosome; $\mathrm{pII} \mathrm{m}=\mathrm{m}$ pseudo-bivalent. $\mathrm{Bar}=10 \mu \mathrm{m}$. 


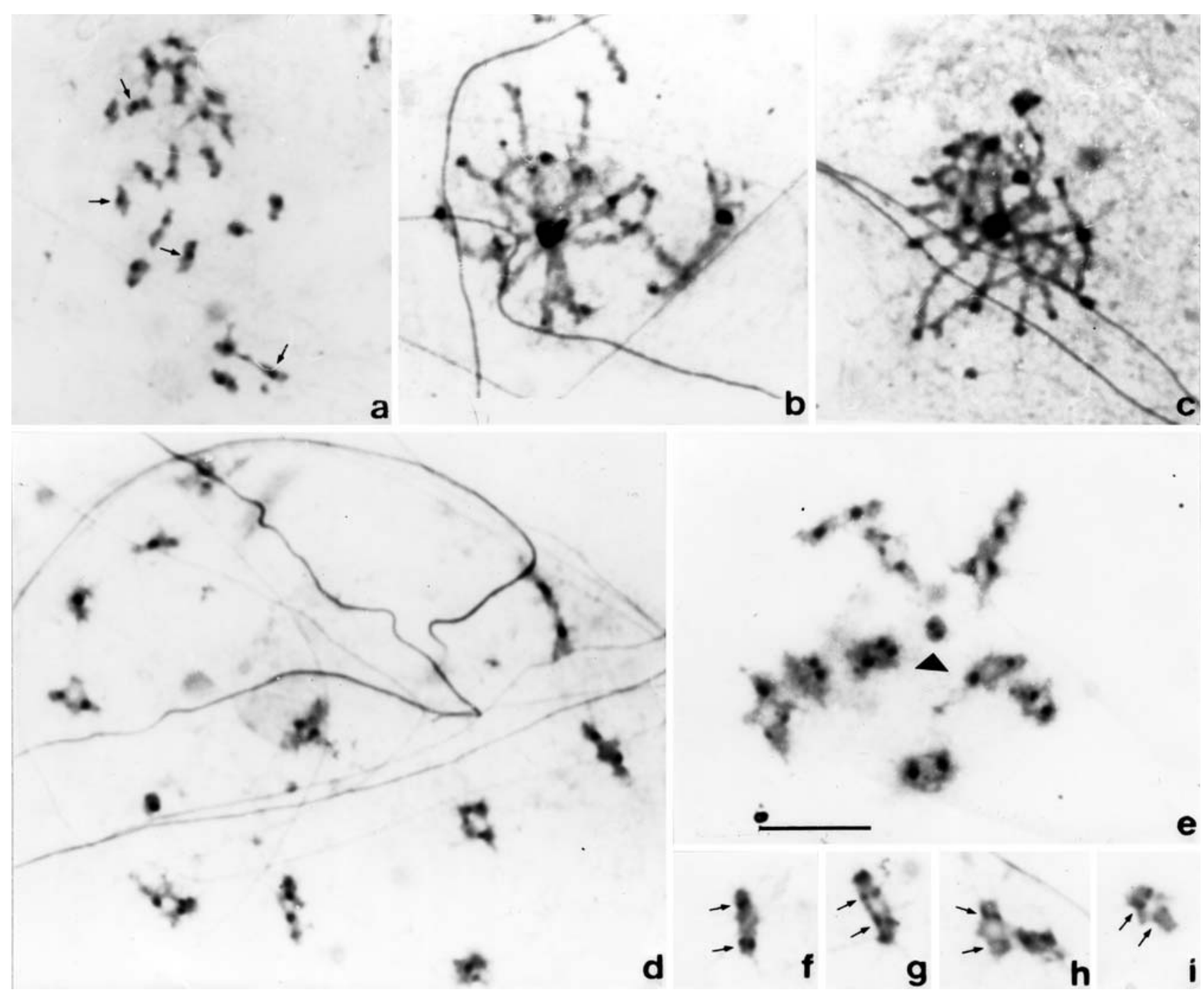

Fig. 3. C-banding in S. batatas. a - spermatogonial mitosis; b-c - pachytene; $\mathrm{d}-\mathrm{e}$ - diakinesis; $\mathrm{f}-\mathrm{i}-$ separate bivalents with interstitial C-positive bands. Arrows indicate interstitial C-positive bands, arrowhead the X chromosomes. Bar $=10 \mu \mathrm{m}$.

\section{DISCUSSION}

\section{Karyotype and meiosis in Spartocera batatas}

The holokinetic nature of heteropteran chromosomes support the hypothesis that fusions and fragmentations are the principal mechanisms of karyotype evolution within the group (Ueshima, 1979; Manna, 1984). Sex chromosome systems described in Heteroptera are simple systems of the type XY/XX $(73.7 \%$ of the more than 1350 species cytogenetically analyzed) or $\mathrm{X} 0 / \mathrm{XX}(14.4 \%)$, and different multiple systems $\left(\mathrm{X}_{\mathrm{n}} \mathrm{Y} / \mathrm{X}_{\mathrm{n}} \mathrm{X}_{\mathrm{n}}, \mathrm{X}_{\mathrm{n}} 0 / \mathrm{X}_{\mathrm{n}} \mathrm{X}_{\mathrm{n}}\right.$, $\left.\mathrm{XY}_{\mathrm{n}} / \mathrm{XX}\right)(11.4 \%)$; neo-systems are very rare and have only been reported in six species (0.5\%) (Ueshima, 1979; Manna et al., 1985; Jacobs, 2004; Papeschi \& Bressa, in press; Rebagliati et al., 2005). The multiple system $\mathrm{X}_{\mathrm{n}} 0 / \mathrm{X}_{\mathrm{n}} \mathrm{X}_{\mathrm{n}}$ is characteristic of the family Coreidae, although it has also been described in a few species of Pyrrhocoridae (10 out of 19 species) and Notonectidae (3 out of 14 species) (Ueshima, 1979; Bressa et al., 1999, 2003; Angus et al., 2004).

$S$. batatas has a diploid chromosome number of $2 n=24$ $=20+2 m+X_{1} X_{2} 0$ (males) which differs from the modal number of the family Coreidae $(2 \mathrm{n}=21=18+2 \mathrm{~m}+\mathrm{X} 0)$ by the presence of an additional autosomal pair and multiple sex chromosomes. A striking feature of the $\mathrm{X}_{\mathrm{n}} 0$ system of $S$. batatas and other species of the family is that the $\mathrm{X}$ chromosomes are generally intimately associated during male meiosis, and in most species the tightly conjoined Xs are positioned outside the ring of autosomes on both metaphase plates. Manna (1984) pointed out that in species with the $\mathrm{X}_{\mathrm{n}} 0$ sex chromosome system the number of $\mathrm{X}$ chromosomes should be confirmed in the spermatogonial complement because during meiosis the multiple Xs generally fuse and form a single element. Similar observations have been made by different authors (Manna, 1951; Dutt, 1957; Parshad, 1957; Fossey \& Liebenberg, 1995).

A previous report on $S$. fusca describe a male chromosome complement of $2 \mathrm{n}=20+2 \mathrm{~m}+\mathrm{X} 0$, with an X chromosome showing a particular morphology (butterfly-shaped); this morphology was interpreted as the $\mathrm{X}$ chromosome having a conspicuous secondary constriction (Cattani \& Papeschi, 2004). The present observations 


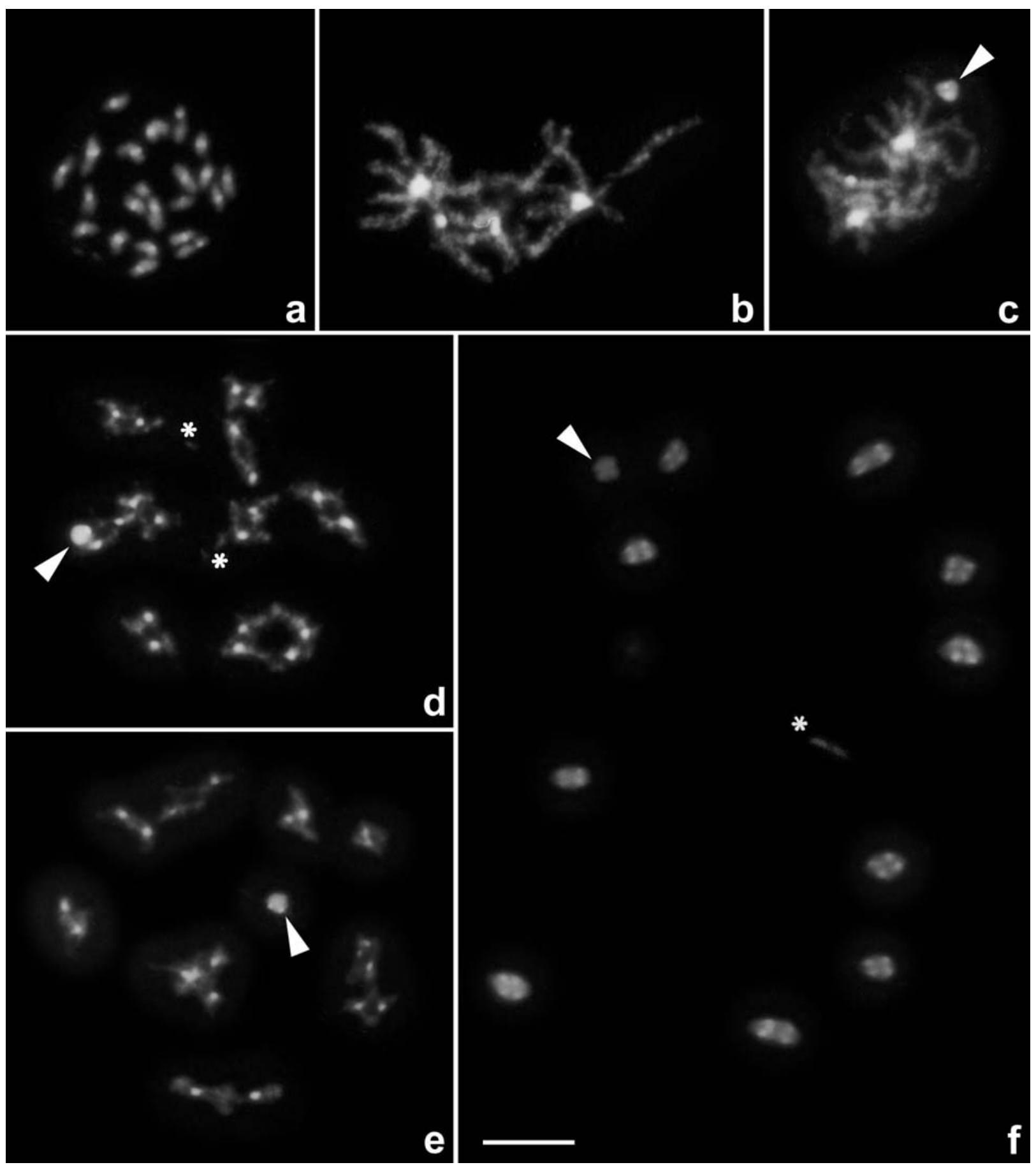

Fig. 4. DAPI-banding in S. batatas. a - spermatogonial mitosis; chromosomes show an interstitial DAPI-bright band; b-c pachytene; bivalents are associated at their DAPI-bright regions; d-e - early diakinesis; each sex chromosome has a DAPI-bright band in one telomeric region; $\mathrm{f}-$ metaphase I. Arrowheads indicate the sex chromosomes and asterisks m-chromosomes. Bar $=10$ $\mu \mathrm{m}$.

on $S$. batatas led us to re-examine the male and female gonial prometaphases of $S$. fusca and based on these results we conclude that both species share the same diploid number $2 \mathrm{n}=24 / 26$ (male/female). The fused condition of the $\mathrm{X}_{1} \mathrm{X}_{2}$ chromosomes during male meiosis in $S$. fusca was misinterpreted in a previous paper. Thus, it is necessary to compare diploid chromosome numbers in both male and female mitotic metaphases in order to con- firm the sex chromosome constitution found at meiosis in males of Heteroptera (see Manna, 1984).

If we consider the modal number of $2 n=21$ as the ancestral chromosome number in Coreidae, the karyotype of $S$. fusca and $S$. batatas probably originated through the fragmentation of one autosomal pair (increasing the number of autosomes from 18 to 20 ), and the fragmentation of the atavic $\mathrm{X}$ chromosome in two unequally sized 
chromosomes, giving rise to a multiple sex chromosome system $\mathrm{X}_{1} \mathrm{X}_{2} 0$ (males).

In both species, each homologue of one of the largest autosomal pairs has a secondary constriction representing the nucleolus organizing region (NOR) (Cattani \& Papeschi, 2004). Another interesting feature of both species is the presence of a semi-persistent nucleolus, which can be detected until the end of the meiosis. The persistence of the nucleolus could be related to intense transcriptional activity necessary for the production of rRNA required for spermiogenesis (García Tavares \& Vilela de AzeredoOliveira, 1997).

A notable difference between the species is the presence of large heterochromatic C-positive and DAPIbright blocks in $S$. batatas and their complete absence in S. fusca (Cattani \& Papeschi, 2004). Furthermore, the location of heterochromatin in an interstitial position in $S$. batatas disagrees with most reports for Heteroptera in which C-heterochromatin characterization has been performed. It has been suggested that the principle of equilocal heterochromatin distribution of Heitz (Heitz, 1933, 1935) (i.e. the tendency of heterochromatin of nonhomologous chromosomes to be located at similar positions) is also characteristic of heteropteran species since C-positive heterochromatin is generally located in telomeric positions (Papeschi, 1991; Panzera et al., 1995; Cattani et al., 2004; Bressa et al., 2005). However, a different pattern was recently reported in a few species. While most bands were terminally located in Tenagobia fuscata (Stål) (Corixidae), Triatoma patagonica Del Ponte (Reduviidae), Petillia patullicollis Walk. (Coreidae) and Nezara viridula (Linnaeus) (Pentatomidae), one autosomal pair in these species presented a conspicuous C-positive band in an interstitial position, corresponding at least in the latter species to the NOR (Camacho et al., 1985; Dey \& Wangdi, 1990; Panzera et al., 1997; Ituarte \& Papeschi, 2004). The analysis of 13 species of Tingidae and four species of Nabis Latreille (Nabidae) using C-banding revealed the presence of very scarce C-positive heterochromatin located either in telomeric or, in some chromosomes, in interstitial positions (Grozeva \& Nokkala, 2003; Grozeva et al., 2004).

It can be concluded that the heterochromatin distribution pattern of $S$. batatas, with large blocks in interstitial positions in all the autosomes, differs from that typical for Heteroptera, and contrasts with the complete absence of heterochromatin in S. fusca. It is certain that the accumulation of heterochromatin in the karyotype of $S$. batatas is not random, but further studies are needed to clarify the possible function of heterochromatin in the genome of Heteroptera.

\section{Sex chromosome systems in Coreidae}

Heteroptera are cytologically unique in that autosomes, m-chromosomes and sex chromosomes have a different meiotic behaviour. Furthermore, different sex chromosome systems may differ with respect to some details in their behaviour and the position that the sex chromosomes occupy on both meiotic metaphase plates.
The meiotic behaviour of the $\mathrm{X}$ chromosomes in $\mathrm{X}_{\mathrm{n}} \mathrm{Y}$ and $\mathrm{X}_{\mathrm{n}} 0$ systems in Heteroptera is different. In $\mathrm{X}_{\mathrm{n}} \mathrm{Y}$ systems the sex chromosomes behave as univalents during male meiosis I, and although they appear sometimes temporarily associated, they behave independently during the first meiotic division. At anaphase I they divide equationally and at metaphase II they associate forming a pseudotrivalent (in $\mathrm{X}_{1} \mathrm{X}_{2} \mathrm{Y}$ systems) or pseudo-multivalent (in $\mathrm{X}_{\mathrm{n}} \mathrm{Y}$ systems) that occupies the centre of the metaphase plate; they divide reductionally at anaphase II, segregating the $\mathrm{X}$ chromatids and the $\mathrm{Y}$ chromatid to opposite poles. This double-plate arrangement at metaphase II is characteristic of well established multiple sex chromosome systems, because in those of recent origin linear orientations and irregular segregations can occur (Papeschi, 1996). On the contrary, in the $X_{n} 0$ systems of Coreidae the $\mathrm{X}$ chromosomes are so intimately associated during male meiosis that they can not be recognized as different entities. The Xs chromatin mass lies outside the metaphase plate during the first meiotic division and divides equationally at anaphase I, but the non-sister chromatids remain tightly associated. At metaphase II they lie outside the plate, and at anaphase II both $\mathrm{X}_{1}$ and $\mathrm{X}_{2}$ chromatids migrate to the same pole. The sex chromosomes decondense at telophase II but later then autosomes.

At the ultrastructural level and with reference to the association during meiosis Solari (1979) showed that axial elements of the synaptonemal complex (SC) are absent in the $\mathrm{X}$ and $\mathrm{Y}$ sex chromosomes of Triatoma infestans (Klug), while the autosomes form SCs; similar observations are reported by Suja and collaborators in three species, with $\mathrm{X}_{1} \mathrm{X}_{2} \mathrm{Y}, \mathrm{X} 0$ and $\mathrm{X}_{1} \mathrm{X}_{2} 0$ male sex chromosomes, suggesting that at least for the holocentric chromosomes of Heteroptera, the axial elements are not directly responsible for sister chromatid cohesion during meiosis I (Suja et al., 2000). More recently, immunolabelling techniques revealed that the meiotic protein Rec 8 is also absent from the cohesin complex in the sex chromosomes of T. infestans and T. pallidipennis Stål (Pigozzi \& Solari, 2003).

The allocycly of the sex chromosomes with respect to the autosomes (and the m-chromosomes) suggests the presence of a condensin-cohesin complex with different composition and/or regulation in these chromosomes. In $\mathrm{XY}$ systems, the association at metaphase II in a pseudobivalent assures a correct segregation, and the sex chromosomes can behave independently during meiosis I. In $\mathrm{X}_{1} \mathrm{X}_{2} \mathrm{O}$ systems the mechanism that assures the correct segregation is the close non-homologous association during the whole of meiosis. It is still unknown how this association is achieved but it probably involves a condensin-cohesin complex different from the one that keeps sister chromatids and homologous chromosomes together during meiosis. We suggest that this latter behaviour (intimate association of the $\mathrm{X}$ chromosomes) was selected for during evolution as an alternative way of segregating sex chromosomes during male meiosis. Further studies at the ultrastructural level are necessary for under- 
standing the general mechanisms governing chromosome behaviour in holokinetic systems.

ACKNOWLEDGEMENTS. The present study was supported from the Buenos Aires University grant X317 and by grants PIP 02296, PEI 6380, and PIP 5261 from CONICET (Buenos Aires).

\section{REFERENCES}

Angus R.B., Kemeny C.K. \& Wood E.L. 2004: The C-banded karyotypes of the four British species of Notonecta L. (Heteroptera: Notonectidae). Hereditas 140: 134-138.

Bressa M.J., Papeschi A.G., Mola L.M. \& Larramendy M.L. 1999: Meiotic studies in Dysdercus Guérin Méneville 1831 (Heteroptera: Pyrrhocoridae). I. Neo-XY in Dysdercus albofasciatus Berg 1878, a new sex chromosome determining system in Heteroptera. Chromosome Res. 7: 503-508.

Bressa M.J., Papeschi A.G., Mola L.M. \& Larramendy M.L. 2001: Autosomal univalents as a common meiotic feature in Jadera haematoloma and Jadera sanguinolenta (Heteroptera: Rhopalidae: Serinethinae). Eur. J. Entomol. 98: 151-157.

Bressa M.J., Papeschi A.G., Fumagalli E., Van Doesburg P.H. \& LaRRAmendy M. 2003: Cytogenetic and nucleolar meiotic cycle analyses in Dysdercus imitator Blöte, 1931 (Heteroptera, Pyrrhocoridae) from Argentina. Folia Biol. 51: 135-141.

Bressa M.J., Larramendy M. \& Papeschi A.G. 2005: Heterochromatin characterization in five species of Heteroptera. Genetica 124: 307-317.

CAmacho J.P.M., Belda J. \& CABrero J. 1985: Meiotic behaviour of the holocentric chromosomes of Nezara viridula (Insecta, Heteroptera) analysed by C-banding and silver impregnation. Can. J. Genet. Cytol. 27: 490-497.

Cattani M.V. \& Papeschi A.G. 2004: Nucleolus organizing regions and semipersistent nucleolus during meiosis in Spartocera fusca (Thurnberg) (Coreidae, Heteroptera). Hereditas 140: $105-111$.

Cattani M.V., Greizerstein E.J. \& Papeschi A.G. 2004: Male meiotic behaviour and nucleolus organizing regions in Camptischium clavipes (Fabr.) (Coreidae, Heteroptera) analyzed by fluorescent banding and in situ hybridization. Caryologia 57: 267-273.

Dey S.K. \& Wangdi T. 1990: Banding patterns of the holocentric chromosomes in some species of Heteroptera. Cytologia 55: $181-186$.

DutT M.K. 1957: Cytology of three species of coreid bugs with special reference to multiple sex chromosome mechanism. Genetica 29: 110-119.

Fossey A. \& Liebenberg H. 1995: Meiosis and nucleolar structures in the stink bug Carlisis wahlbergi Stål (Coreidae: Heteroptera). Cytobios 81: 7-15.

García Tavares M. \& Vilela de Azeredo-Oliveira M.T. 1997: Pattern of nucleolar activity during spermiogenesis in triatomines (Heteroptera, Reduviidae) as analysed by silver staining. Cytobios 89: 93-103.

González-García J.M., Antonio C., Suja J.A. \& Rufas J.S. 1996: Meiosis in holocentric chromosomes: kinetic activity is randomly restricted to the chromatid ends of sex univalents in Graphosoma italicum (Heteroptera). Chromosome Res. 4: 124-132.

Grozeva S. \& NokKala S. 2001: Chromosome numbers, sex determining systems, and patterns of the C-heterochromatin distribution in 13 species of lace bugs (Heteroptera, Tingidae). Folia Biol. 49: 29-41.
Grozeva S. \& Nokkala S. 2003: C-heterochromatin and extra (B) chromosome distribution in six species of the Nabis (Heteroptera, Nabidae) with the modal male karyotype $2 \mathrm{n}=16+$ XY. Folia Biol. 51: 13-21.

Grozeva S., Kuznetsova V.G. \& Nokkala S. 2004: Patterns of chromosome banding in four nabid species (Heteroptera, Cimicomorpha, Nabidae) with high chromosome number karyotypes. Hereditas 140: 99-104.

HeITz E. 1933: Die somatischen Heteropyknose bei Drosophila melanogaster und ihre genetische Bedeutung. Z. Zellforsch. 20: 237-287.

Hertz E. 1935: Die Herkunft der Chromozentren. Planta 18: 571-635.

Ituarte S. \& Papeschi A.G. 2004: Achiasmatic male meiosis in Tenagobia (Fuscagobia) fuscata (Heteroptera, Corixoidea, Micronectidae). Genetica 122: 199-206.

$J_{A C O B S}$ D.H. 2004: The evolution of a neo- $\mathrm{XY}_{1} \mathrm{Y}_{2}$ sex chromosome system by autosome-sex chromosome fusion in Dundocoris nodulicarinus Jacobs (Heteroptera: Aradidae: Carventinae). Chromosome Res. 12: 175-191.

ManNA G.K. 1951: A study of the chromosomes during meiosis in forty-three species of Indian Heteroptera. Proc. Zool. Soc. Bengal 4: 1-116.

ManNa G.K. 1984: Chromosomes in evolution in Heteroptera. In Sharma A.K. \& Sharma A. (ed.): Chromosomes in Evolution of Eukaryotic Groups. CRC Press, Boca Raton, FL, pp 189-225.

Manna G.K., Ueshima N., Dey S.K. \& Deb-Mallik S. 1985: Marked sex chromosomal variations between Indian and Japanese species of Physopelta (Largidae, Heteroptera). Cytologia 50: 621-630.

NoKKaLA S. 1986: The mechanisms behind the regular segregation of the $\mathrm{m}$ chromosomes in Coreus marginatus $\mathrm{L}$. (Coreidae, Hemiptera). Hereditas 105: 73-85.

Panzera F., Perez R., Panzera Y., Alvarez F., Scvortzoff E. \& Salvatella R. 1995: Karyotype evolution in holocentric chromosomes of three related species of triatomines (Hemiptera: Reduviidae). Chromosome Res. 3: 143-150.

Panzera F., Hornos S., Pereira J., Cestau R., Canale D., Diotaiuti L., Dujardin J.P. \& Perez R. 1997: Genetic variability and geographic differentiation among three species of triatominae bugs (Hemiptera: Reduviidae). Am. J. Trop. Med. Hyg. 57: 732-739.

PAPESCHI A.G. 1988: C-banding and DNA content in three species of Belostoma (Heteroptera) with large differences in chromosome size and number. Genetica 76: 43-51.

PAPESCHI A.G. 1991: DNA content and heterochromatin variation in species of Belostoma (Heteroptera, Belostomatidae). Hereditas 115: 109-114.

PAPESCHI A.G. 1994: Chromosome rearrangements in Belostoma plebejum (Belostomatidae, Heteroptera). Caryologia 47: 223-230.

PAPESCHI A.G. 1996: Sex chromosome polymorphism in species of Belostoma (Belostomatidae, Heteroptera). Hereditas 124: 269-274.

PAPESCHI A.G. \& BRessa M.J. (in press): Evolutionary cytogenetics in Heteroptera. J. Biol. Res.

Papeschi A.G., Mola L.M., Bressa M.J., Greizerstein E.J., Lia V. \& Poggio L. 2003: Behaviour of ring bivalents in holokinetic systems: alternative sites of spindle attachment in Pachylis argentinus and Nezara viridula (Heteroptera). Chromosome Res. 11: 725-733.

PARSHAD R. 1957: Chromosome number and sex mechanism in twenty species of the indian Heteroptera. Curr. Sci. 16: 125. 
Pigozzi M.I. \& Solari A.J. 2003: Differential immunolocalization of a putative Rec8p in meiotic autosomes and sex chromosomes of triatomine bugs. Chromosoma 112: 38-47.

Rebagliati P., Papeschi A.G. \& Mola L.M. 2003: Meiosis and fluorescent banding in Edessa meditabunda and E. rufomarginata (Heteroptera: Pentatomidae: Edessinae). Eur. J. Entomol. 100: $11-18$.

Rebagliati P., Mola L.M., Papeschi A.G. \& Grazia J. 2005: Cytogenetic studies in Pentatomidae (Heteroptera): A review. J. Zool. Syst. Evol. Res. 43: 199-213.

Schaefer C.W. \& Panizzi A.R. 2000: Heteroptera of Economic Importance. CRC Press, Boca Raton, FL, 828 pp.

Schun R.T. \& Slater J. 1995: True Bugs of the World (Hemiptera: Heteroptera): Classification and Natural History. Cornell University Press, New York, 349 pp.

Solari A.J. 1979: Autosomal synaptonemal complexes and sex chromosomes without axes in Triatoma infestans (Reduviidae; Hemiptera). Chromosoma 72: 225-240.
Suja J.A., Del Cerro A.L., Page J., Rufas J.S. \& Santos J.L. 2000: Meiotic sister chromatid cohesion in holocentric sex chromosomes of three heteropteran species is maintained in absence of axial elements. Chromosoma 109: 35-43.

Ueshima N. 1979: Hemiptera II: Heteroptera. In John B. (ed.): Animal Cytogenetics. Gebrüder Borntraeger, Berlin, Stuttgart, $\mathrm{v}+117 \mathrm{pp}$.

WILSON E.B. 1907: The supernumerary chromosomes of Hemiptera. Science 26: 870-871.

WILSON E.B. 1909: Studies on chromosomes. V. The chromosomes of Metapodius. A contribution to the hypothesis of the genetic continuity of chromosomes. J. Exp. Zool. 6: 147-205.

XAVIER A. 1945: Cariologia comparada de alguns Hemipteros Heteropteros (Pentatomoideos e Coreideos). Mem. Estud. Mus. Zool. Univ. Coimbra 163: 1-105.

Received August 22, 2005; revised and accepted October 16, 2005 